\title{
Caffeine Alters Blood Potassium and Catecholamine Concentrations but not the Perception of Pain and Fatigue with a 1 km Cycling Sprint
}

\author{
Dean M. Cordingley (Corresponding author) \\ Pan Am Clinic Foundation, 75 Poseidon Bay, Winnipeg R3M 3E4, Canada \\ E-mail: dcordingley@panamclinic.com \\ Gordon J. Bell \\ Faculty of Physical Education \& Recreation, University of Alberta, Edmonton T6G 2H9, Canada \\ E-mail: Gordon.bell@ualberta.ca \\ Daniel G. Syrotuik \\ Faculty of Physical Education \& Recreation, University of Alberta, Edmonton T6G 2H9, Canada \\ E-mail: dan.syrotuik@ualberta.ca
}

Received: 25-03- 2016

Accepted: 18-06- 2016

Published: 31-07- 2016

doi:10.7575/aiac.ijkss.v.4n.3p.1

URL: http://dx.doi.org/10.7575/aiac.ijkss.v.4n.3p.1

\begin{abstract}
Background: Caffeine has been used by some athletes to improve short-term high-intensity exercise performance; however, the literature is equivocal. Objectives: The objective of this study was to investigate the effects of caffeine on plasma potassium and catecholamine concentrations, pain and fatigue perception, to determine whether potassium ion handling and altered perception related to the central nervous system are associated with enhanced performance during a $1 \mathrm{~km}$ cycling time trial. Methods: Thirteen well trained men with a mean age of $27 \pm 6$ yrs (body mass: $76.4 \pm 6.4$ $\mathrm{kg}$, height: $180 \pm 7 \mathrm{~cm}$, and $\mathrm{VO}_{2} \max : 57.5 \pm 4.6 \mathrm{ml} \cdot \mathrm{kg}^{-1} \cdot \mathrm{min}^{-1}$ ) were recruited. Participants were randomized to a caffeine $\left(5 \mathrm{mg} \cdot \mathrm{kg}^{-1}\right)$ or a placebo condition using a double blind, cross over design. Results: Caffeine had no significant effects on the $1 \mathrm{~km}$ time-trial performance indicators of time $(82.1 \pm 2.4 \mathrm{vs} .81 .9 \pm 3.9 \mathrm{~s})$, peak $(633.0 \pm 83.6$ vs. $638.7 \pm 110.1$ watts $)$ or average power $(466.0 \pm 37.3$ vs. $467.5 \pm 59.9$ watts; caffeine and placebo conditions respectively). In addition, caffeine had no significant effect on oxygen consumption $\left(\dot{\mathrm{VO}}_{2}\right)(4.11 \pm 0.24 \mathrm{vs} 4.06 \pm$ $0.29 \mathrm{~L})$, the perception of pain $(5.6 \pm 2.4 \mathrm{vs} .5 .5 \pm 2.6)$ or fatigue $(7.1 \pm 1.8 \mathrm{vs} .7 .1 \pm 1.8$ : caffeine and placebo conditions respectively). There was a significantly greater increase in post-exercise blood lactate $(\mathrm{p}<0.05)$ and catecholamines $(\mathrm{p}<0.05)$ as well as a lower pre-exercise blood potassium concentration $(\mathrm{p}<0.05)$ in the caffeine condition. Conclusions: The results suggest that caffeine can enhance certain metabolic parameters, but these changes were unable to augment short-distance $(1 \mathrm{~km})$, high-intensity cycling performance.
\end{abstract}

Keywords: ergogenic, anaerobic exercise, performance, oxygen consumption

\section{Introduction}

\subsection{Review of Literature}

Caffeine has been used as a supplement to improve exercise performance of various durations and intensities. Caffeine is ergogenic for aerobic (Bridge \& Jones, 2006; Cox et al., 2002; Graham et al., 1998; Ivy et al., 2009) and anaerobic events (Anderson et al., 2000; Anselme et al., 1992; Wiles et al., 2006; Wiles et al, 1992). The two most widely accepted hypotheses supporting the purported ergogenic properties of caffeine have been associated with changes in peripheral potassium ion handling and an altered central nervous system perception (Davis \& Green, 2009; Doherty, Smith, Davison, \& Hughes, 2002; Greer, McLean, \& Graham, 1998). A decrease in plasma potassium during aerobic exercise has been used to indirectly indicate maintenance of the sodium/potassium electrochemical gradient in skeletal muscle, permitting the muscle to maintain the force of contraction better under fatiguing conditions (Davis \& Green, 2009; Lindinger et al, 1993; Spriet \& Howlett, 2000). However, little research has investigated the effects of caffeine on plasma potassium levels after short-term high-intensity exercise (Davis \& Green, 2009).

Caffeine also influences the central nervous system via an increase in catecholamines (Berkowitz et al., 1970) that were greater during high intensity anaerobic exercise compared to placebo (Bell et al., 2001; Doherty et al., 2002; Greer et al., 1998). Caffeine also inhibits adenosine receptors in smooth and skeletal muscle (Lynge \& Hellsten, 2000; Smith, 2003) which can reduce the perception of exercise-induced pain (Davis \& Green, 2009; Spriet \& Howlett, 2000). 
Previous work by Wiles et al. (2006) showed that pre-race caffeine consumption can improve $1 \mathrm{~km}$ cycling time trial performance, but did not attempt to elicit the mechanism by which caffeine acts. The combination of decreased plasma potassium coupled with diminished perceived pain and fatigue with increases in plasma catecholamines and caffeine's antagonistic effect on adenosine receptors may contribute to enhanced short-term high-intensity exercise performance.

\subsection{Purpose of the Study}

The purpose of this study was to investigate the effects of caffeine on pain and fatigue perception, plasma catecholamine and potassium concentrations to determine whether altered central nervous system perception and/or potassium ion handling were associated with any changes in performance during a $1 \mathrm{~km}$ cycling time trial in trained cyclists. It was hypothesized that caffeine supplementation would produce a faster $1 \mathrm{~km}$ time-trial in conjunction with both a lower pain and fatigue ratings coupled with an increase in plasma catecholamines and attenuated increases in plasma potassium compared to placebo.

\section{Methods}

\subsection{Participants}

Thirteen trained males (age: $27 \pm 6$ yrs, body mass: $76.4 \pm 6.4 \mathrm{~kg}$, height: $180 \pm 7 \mathrm{~cm}$, and $\mathrm{VO}_{2}$ max: $57.5 \pm 4.6 \mathrm{ml} \cdot \mathrm{kg}^{-}$ ${ }^{1} \cdot \mathrm{min}^{-1}$ ) with cycling experience were recruited from a University student population and various local cycling clubs. All participants were habituated caffeine users. Each participant was screened using the Physical Activity Readiness Questionnaire (PAR-Q), a participant information letter and an orientation meeting where all study procedures were verbally explained. Written consent was obtained at pre-screening and all procedures were approved by a University Research Ethics Board.

\subsection{Experimental Design}

A randomized double-blind, crossover design was utilized requiring all participants to complete both placebo and experimental (caffeine) conditions on separate days after a washout period. The data was collected over three separate visits to the laboratory, with a minimum seven days recovery between each visit.

\subsection{Procedures}

During session 1, the participants arrived at the lab to familiarize themselves with the procedures of the study. Following this, a graded exercise test (GXT) was performed on a Velotron stationary cycle (Racer Mate, Seattle, WA, U.S.A.) to determine maximal oxygen consumption ( $\dot{\mathrm{VO}}_{2}$ max). The GXT was done to determine a power output equivalent to $20 \%$ of the participant's $\dot{\mathrm{VO}}_{2 \text { max }}$ which was used to prescribe the intensity of the recovery exercise following the $1 \mathrm{~km}$ cycling time trial. The GXT began at a power output of 100 watts which was increased by 25 watts every minute until volitional exhaustion (Elliott \& Grace, 2010). Expired gases were collected and analyzed for $\mathrm{O}_{2}$ and $\mathrm{CO}_{2}$ with a metabolic cart (Parvo Medics TrueOne 2400, Utah) that was previously calibrated for volume of air as well as before and after each test with known gas concentrations. Heart rate was recorded every minute from a heart rate monitor (Polar Electro, Finland). $\dot{\mathrm{VO}}_{2}$ max was determined as the point at which there was a peak and plateau in oxygen uptake $(<100 \mathrm{~mL} / \mathrm{min})$ with increasing power output or duration of exercise that was also associated with secondary criteria including a respiratory exchange ratio (RER) greater than 1.1, a heart rate $\geq$ age-predicted maximum and volitional exhaustion (Howley et al., 1995). Each participant was fitted to the Velotron cycle by adjusting the vertical and horizontal position of the seat and handle bars to mimic their own racing bicycle and cycling shoes/pedal combination. These measurements were recorded for replication during the subsequent experimental trials. Each participant was instructed on the same basic strategy for performing the 1 kilometer time-trial and completed one practice time-trial. On departure from the familiarization session, subjects were instructed to avoid all forms of caffeine, alcohol and intense physical activity for 24 hours prior to the experimental trials. The subjects were asked to record and subsequently consume the same meals the day prior to both experimental sessions.

Sessions 2 and 3 were separated by 7 to 10 days to allow for appropriate wash-out with subjects arriving at the lab between 7 and 10am. A blood sample of $10 \mathrm{~mL}$ was taken via venipuncture at rest, by an individual trained in this procedure. Each subject then consumed a randomly assigned treatment of either a flavored, non-caloric placebo drink (500 $\mathrm{ml}$ of water with Crystal Light, Kraft Canada) or caffeine (Life Brand, Shoppers Drug Mart, Canada) at a serving of $5 \mathrm{mg} \cdot \mathrm{kg}^{-1}$ body mass (Graham, 2001) dissolved in $500 \mathrm{ml}$ of the same flavored drink as the placebo. Following consumption of the drink, each subject rested 1 hour, which has been previously shown to be an effective duration for caffeine absorption into the blood stream (Wiles et al., 2006). The cycle ergometer was set-up according to the previously determined measurements and preferred riding position for each participant. Twenty five minutes before the $1 \mathrm{~km}$ time trial began, an intravenous catheter was inserted into a forearm vein by a registered nurse. The site was kept patent with $0.5 \mathrm{ml}$ of sterile saline $(0.9 \% \mathrm{NaCl})$ and prior to every blood sample, a small $(2-3 \mathrm{ml})$ blood sample was drawn and discarded to ensure that any saline was removed. A $10 \mathrm{ml}$ blood sample was then drawn prior to the 10 minute warm-up consisting of a self-selected sub-maximal intensity but with three prescribed, 5 second sprint intervals included at specific time points. This warm-up protocol was followed by a 5 minute period for the subjects to perform light dynamic stretching and recover with an additional 5 minute period for set up and preparation of the metabolic cart. The warm-up was monitored and remained the same for both experimental trials. Subsequently, another blood sample of $10 \mathrm{ml}$ was taken immediately before the $1 \mathrm{~km}$ time-trial. 
During both $1 \mathrm{~km}$ time-trials, participants were provided with consistent verbal encouragement to provide an all-out effort that would mimic a "race". Subjects were also provided with a visual marker on a computer monitor indicating the distance through the $1 \mathrm{~km}$ time-trial. The participants were not provided with the time of performance at any point throughout or following the $1 \mathrm{~km}$ time-trial. The selected cycle gear ratio was $48 / 14$, which elicited a speed of 40 kilometers per hour at $90 \mathrm{rpm}$ on the Velotron similar to that reported by Wiles et al. (2006). Expired gases were collected during and for 5 minutes after the time trials and analyzed for $\mathrm{O}_{2}$ and $\mathrm{CO}_{2}$ with the same calibrated metabolic cart. Following the $1 \mathrm{~km}$ time trial, $10 \mathrm{ml}$ blood samples were taken immediately after or as soon as feasibly possible, and at 5, 10 and 15 minutes of recovery. The subjects completed a standardized recovery that consisted of cycling at an intensity equivalent to $20 \%$ of the individual's $\mathrm{V}_{2}$ max for 5 minutes followed by a passive recovery sitting on a chair. Following the 5 minute active recovery, the subjects completed the categorical Pain Perception Scale (Cook et al., 1998) and visual analogue fatigue scales (Egerton et al., 2009) while seated.

\subsubsection{Blood procedures \& Assays}

The blood samples were collected in $10 \mathrm{ml}$ syringes and a few drops of blood were immediately placed in an EG7+ cartridge for an Abbot Point of Care i-STAT hand held analyzer (Abbott Laboratories, New Jersey) for the determination of $\mathrm{pH}$ and electrolyte analysis. Also, $0.25 \mathrm{ml}$ of whole blood was immediately pipetted into a disposable culture tube containing $8 \%$ perchloric acid and vortexed for 30 seconds for deproteinization. The remaining blood was placed in a test-tube coated in ethylenediaminetetraacetic acid (EDTA). The deproteinized and EDTA treated blood tubes were subsequently centrifuged for 10 minutes at $1500 \mathrm{xg}$ in a refrigerated centrifuge $\left(4^{\circ} \mathrm{C}\right)$ and then aliquoted into microcentrifuge tubes and frozen immediately at $-20^{\circ} \mathrm{C}$ and then transferred to a $-80^{\circ} \mathrm{C}$ ultra-low freezer until the lab analyses were performed. Blood lactate concentration was determined from the mean of duplicate samples using a standard spectrophotometric assay (Gutmann \& Wahlefeld, 1974). Epinephrine and norepinephrine were determined in duplicate using an enzyme-linked immunosorbent assay kit (ELISA) (Rocky Mountain Diagnostics Inc, Colorado Springs, CO).

\subsubsection{Data and Statistical Analysis}

Sample size was calculated a priori using the primary outcome of performance time. An effect size of 0.82 was calculated (Wiles et al., 2006) with $\alpha=0.05$ and power set at 80\%, requiring a minimum of 12 participants per group. Data from the 2 experimental trials were compared using a two-way ANOVA with repeated measures on both factors (experimental condition by time). A paired t-test was performed to test for mean differences between the $1 \mathrm{~km}$ performance time, power output, fatigue and pain. If a significant F-ratio was determined, a Newman-Keuls multiple comparison procedure was performed. Results were considered significant at $P \leq 0.05$ for all statistical analyses. All data are means \pm standard deviation unless otherwise noted. Statistica, version 8.0 (StatsSoft Inc., Tulsa, OK) was used to perform all statistical analyses. Four subjects had missing data points for potassium and $\mathrm{pH}$ concentrations due to instrument and/or user error and were removed from the statistical analyses of these variables.

\section{Results}

\subsection{Performance Measures}

Caffeine ingestion did not improve time (caffeine vs. placebo: $82.1 \pm 2.4$ vs. $81.9 \pm 3.9$ seconds), peak power output (caffeine vs. placebo: $633.0 \pm 83.6$ vs. $638.7 \pm 110.1$ watts) or average power output (caffeine vs. placebo: $466.0 \pm 37.3$ vs. $467.5 \pm 59.9$ watts) during the $1 \mathrm{~km}$ cycling time trial.

\subsection{Perceived Pain and Fatigue:}

The numerical pain scale revealed that caffeine did not reduce perceived pain immediately following a $1 \mathrm{~km}$ cycling time-trial (caffeine vs. placebo: $5.6 \pm 2.4$ vs. $5.5 \pm 2.6$ ). The fatigue visual analogue scales revealed that caffeine ingestion did not attenuate leg fatigue (caffeine vs. placebo: $7.1 \pm 1.4$ vs. $7.4 \pm 2.0$ ) or overall fatigue (caffeine vs. placebo: $7.1 \pm 1.8$ vs. $7.1 \pm 1.8$ ) compared to the placebo condition.

\subsection{Blood Variables}

Blood lactate concentrations were significantly increased post exercise in both the caffeine and placebo condition when compared to pre- $1 \mathrm{~km}$ cycling time-trial concentrations. Caffeine ingestion caused a greater increase ( $<0.05$; Figure 1 ) in blood lactate concentrations 0,5 and 15 minutes post- $1 \mathrm{~km}$ cycling time-trial compared to the placebo condition. 


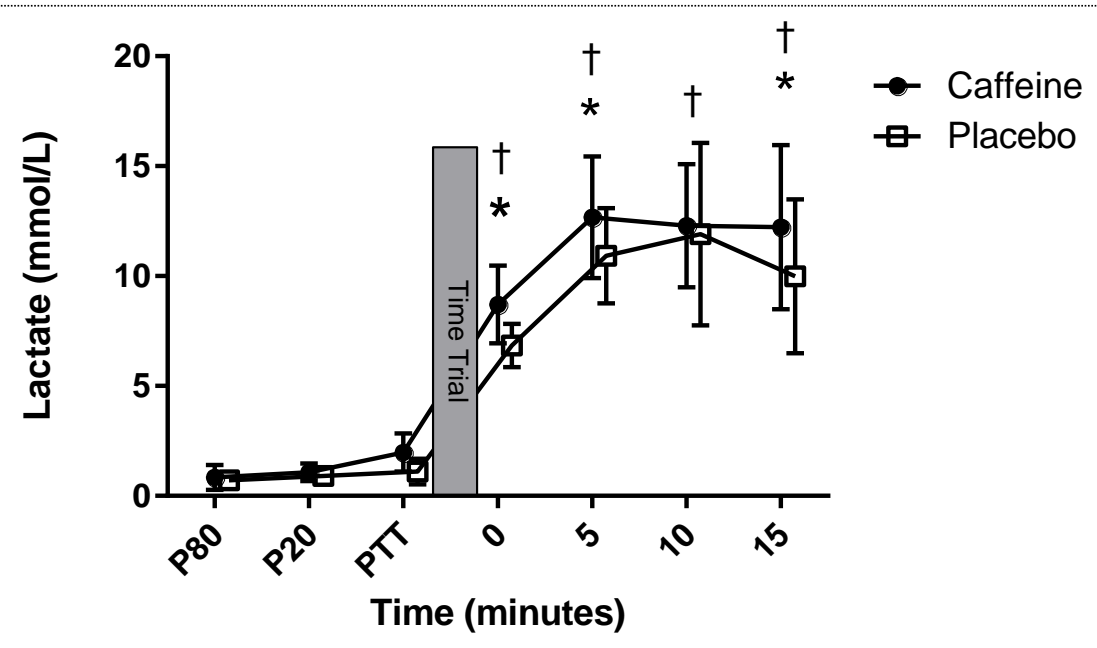

Figure 1. Blood lactate responses (mean $\pm \mathrm{SD} ; \mathrm{n}=13$ ) prior to and during recovery from cycling $1 \mathrm{~km}$ after consuming caffeine or placebo. P80 = 80 minutes pre-time trial; P20 = 20 minutes pre-time trial; PTT=immediate pre-time trial; $\mathrm{TT}=1 \mathrm{~km}$ time trial. * Significant difference between caffeine condition and placebo, $\mathrm{p}<0.05$. $\dagger$ both caffeine and placebo conditions are significantly different from all pre time trial measures.

Caffeine significantly attenuated blood potassium concentrations immediately prior to the $1 \mathrm{~km}$ cycling time-trial compared to the placebo condition (Figure 2). Blood potassium levels were elevated $(\mathrm{p}<0.05)$ immediately following the $1 \mathrm{~km}$ cycling time-trial in both the caffeine and placebo conditions compared to pre-exercise levels.

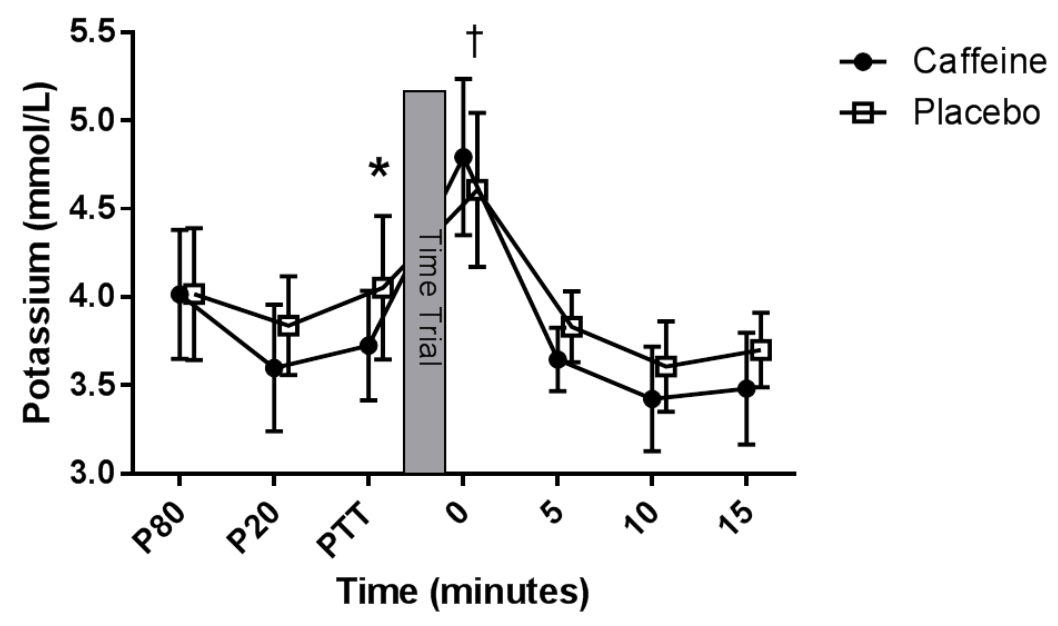

Figure 2. Blood potassium responses (mean $\pm \mathrm{SD}$; $\mathrm{n}=9$ ) prior to and during recovery from cycling $1 \mathrm{~km}$ after consuming caffeine or placebo. P80 = 80 minutes pre-time trial; P20 = 20 minutes pre-time trial; PTT=immediate pre-time trial; $\mathrm{TT}=1 \mathrm{~km}$ time trial. * Significant difference between caffeine condition and placebo, $\mathrm{p}<0.05$. $\dagger$ Significant difference from all other time points.

Blood pH was significantly higher pre-exercise compared to all time points post-exercise in both the caffeine and placebo conditions. Caffeine consumption did not differentially alter $\mathrm{pH}$ levels at any time point when compared with the placebo condition (Figure 3). 


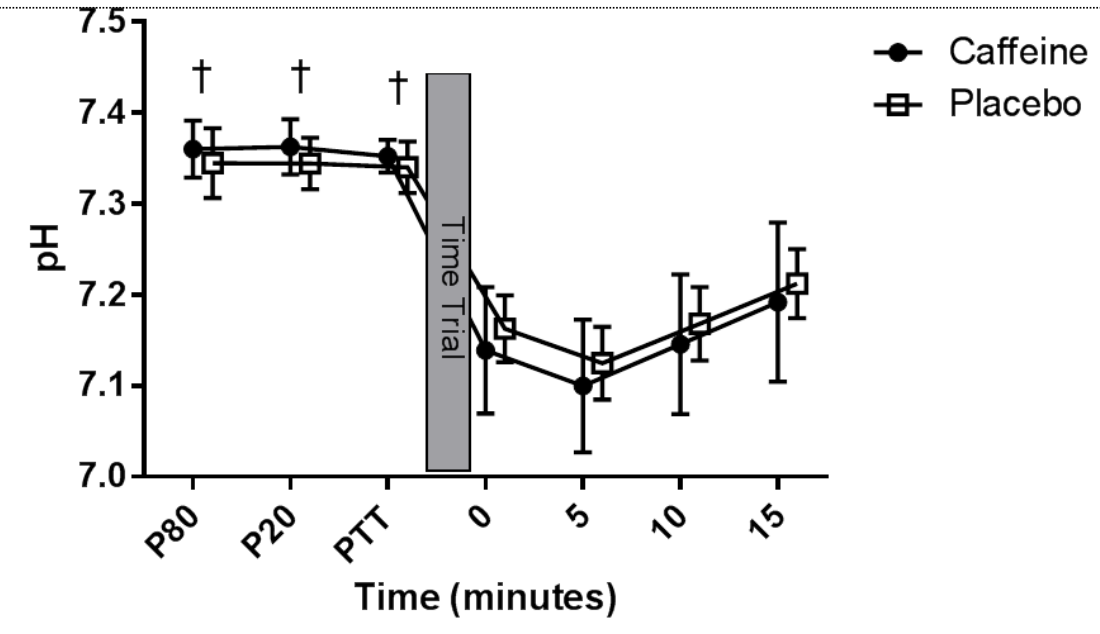

Figure 3. Blood $\mathrm{pH}$ responses (mean $\pm \mathrm{SD}$; $\mathrm{n}=9$ ) prior to and during recovery from cycling $1 \mathrm{~km}$ after consuming caffeine or placebo. P80 = 80 minutes pre-time trial; P20 = 20 minutes pre-time trial; PTT=immediate pre-time trial; $\mathrm{TT}=1 \mathrm{~km}$ time trial. $\dagger$ both caffeine and placebo conditions are significantly different from all post time trial measures.

Epinephrine concentration in the blood was significantly increased immediately post-exercise as well as 5 minutes postexercise compared to all pre-exercise time points, the 10 minute post-exercise and the 15 minute post-exercise time points in both placebo and caffeine conditions. Epinephrine concentration was significantly higher in the caffeine trial immediately following the $1 \mathrm{~km}$ cycling time-trial as well as 5 minutes post-exercise when compared to the placebo condition (Figure 4).

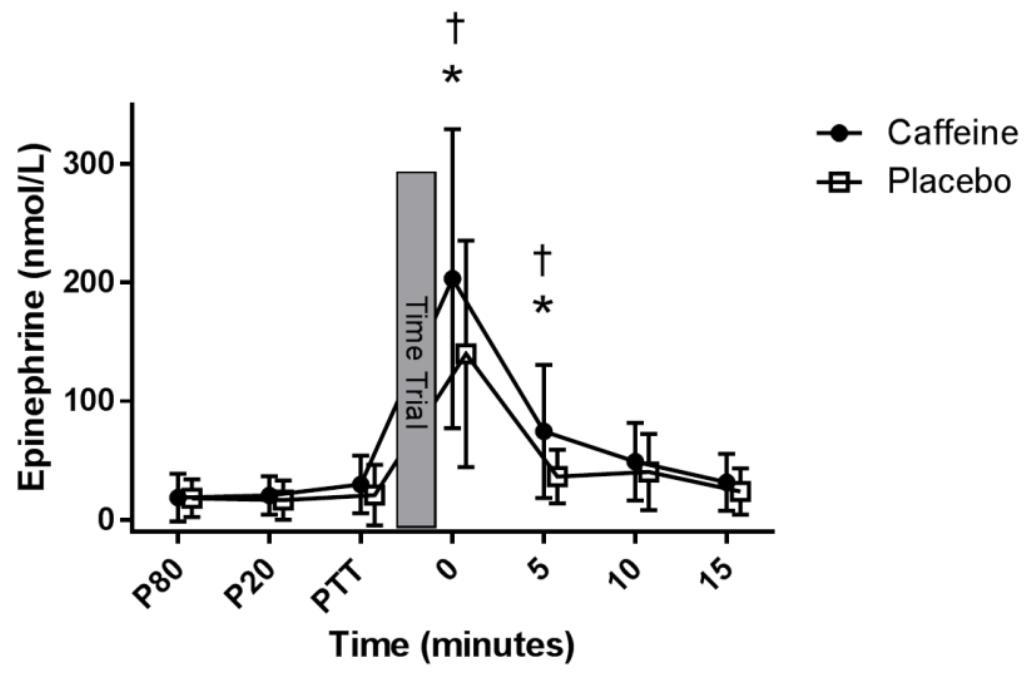

Figure 4. Blood epinephrine (Epi) responses (mean $\pm \mathrm{SD} ; \mathrm{n}=13$ ) prior to and during recovery from cycling $1 \mathrm{~km}$ after consuming caffeine or placebo. P80 $=80$ minutes pre-time trial; $\mathrm{P} 20=20$ minutes pre-time trial; PTT=immediate pretime trial; TT=1 km time trial. * Significant difference between caffeine condition and placebo, $\mathrm{p}<0.05$. $\dagger$ significantly different than all other time points.

Immediately post-exercise, as well as 5 minutes and 10 minutes post-exercise, norepinephrine concentrations were increased in the blood when compared to all pre-exercise time points in both the caffeine and placebo conditions $(\mathrm{p}<0.05)$. Caffeine consumption increased norepinephrine concentrations immediately following the $1 \mathrm{~km}$ cycling timetrial as well as 5 minutes post-exercise greater than the placebo condition (Figure 5). 


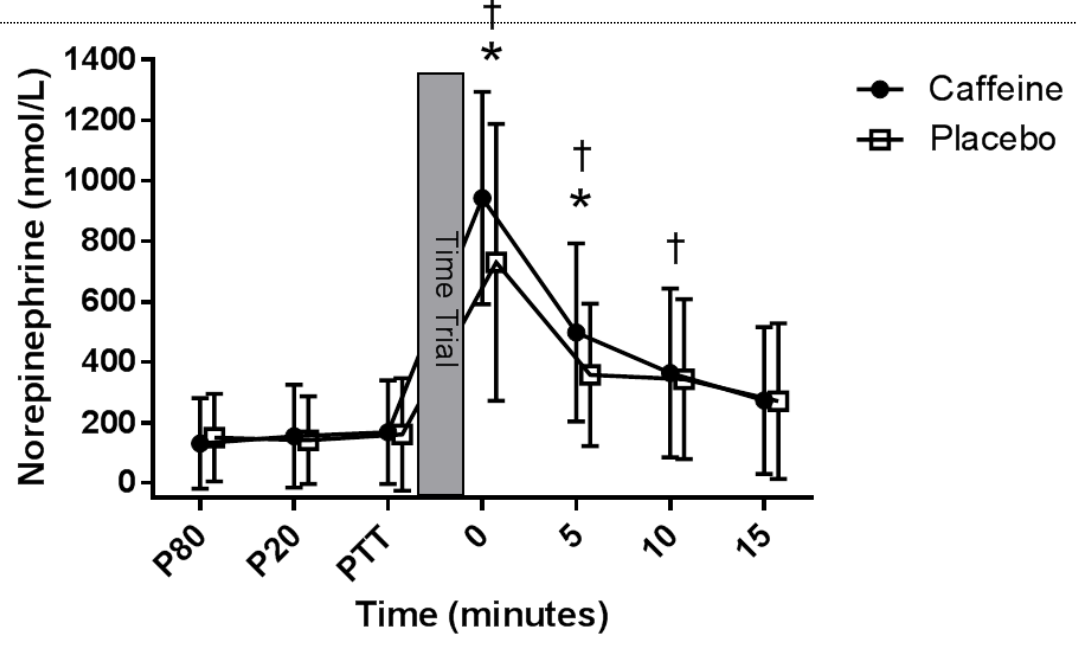

Figure 5. Blood norepinephrine (Nor) responses (mean $\pm \mathrm{SD}$; $=13$ ) prior to and during recovery from cycling $1 \mathrm{~km}$ after consuming caffeine or placebo. $\mathrm{P} 80=80$ minutes pre-time trial; $\mathrm{P} 20=20$ minutes pre-time trial; PTT=immediate pre-time trial; TT $=1 \mathrm{~km}$ time trial. * Significant difference between caffeine condition and placebo, $\mathrm{p}<0.05$. $\dagger$ both caffeine and placebo conditions significantly different from pre time trial measure.

\subsection{Oxygen Consumption}

There was a significant increase in $\mathrm{VO}_{2}$ during the time trial, peaking at 53.1 and $52.2 \mathrm{ml} \cdot \mathrm{kg}^{1} \cdot \mathrm{min}^{1}$ for caffeine and placebo conditions representing $92 \%$ and $91 \%$ of $\mathrm{VO}_{2}$ max , respectively. Caffeine had no significant effect on $\mathrm{VO}_{2}$ prior to or during the time trial, and despite $\mathrm{VO}_{2}$ being slightly higher during recovery in the caffeine condition, the response was not significant (Table 1).

Table 1. Oxygen uptake $\left(\mathrm{VO}_{2} ; \mathrm{L}\right)$ before, during and throughout recovery from the $1 \mathrm{~km}$ time trial (TT). Values are mean \pm SD.

\begin{tabular}{cccc}
\hline Condition & $\mathrm{VO}_{2}(\mathrm{~L}) 1$ min before the 1 \\
$\mathrm{~km} \mathrm{TT}$ & $\begin{array}{c}\text { Total } \mathrm{VO}_{2}(\mathrm{~L}) \text { during the } 1 \mathrm{~km} \\
\mathrm{TT}\end{array}$ & 5 min total recovery $\mathrm{VO}_{2}(\mathrm{~L})$ \\
\hline Caffeine & $0.49 \pm 0.12$ & $4.11 \pm 0.24^{*}$ & $10.09 \pm 1.26^{* *}$ \\
Placebo & $0.49 \pm 0.09$ & $4.06 \pm 0.29^{*}$ & $9.86 \pm 1.33^{* *}$ \\
\hline
\end{tabular}

* significantly higher than before the $1 \mathrm{~km} \mathrm{TT,} \mathrm{P}<0.05$.

** significantly higher than before and during the $1 \mathrm{~km} \mathrm{TT,} \mathrm{P}<0.05$.

\section{Discussion}

Athletes in a variety of sports consume caffeine and products containing caffeine to enhance their exercise performance (Burke, 2008; Spriet, 2014). Caffeine's ability to improve longer duration aerobic activities (i.e., $>5$ minutes) is well established while caffeine's effects on short-term high-intensity activities are less conclusive (Davis \& Green, 2009). This study examined whether caffeine supplementation would produce a faster $1 \mathrm{~km}$ time trial in conjunction with both a lower perceived pain and fatigue rating coupled with an increase in plasma catecholamine concentrations and attenuated increases in plasma potassium concentrations, when compared to a placebo condition. The findings of this study demonstrated that caffeine ingestion, at a dose of $5 \mathrm{mg} \cdot \mathrm{kg}^{-1}$ body mass, did not elicit improved performance time, peak power or average power output during a $1 \mathrm{~km}$ cycling time-trial. These findings corroborate previous research which also found no performance improvements in short term high intensity exercise combined with caffeine supplementation (Buck et al., 2015; Crowe et al., 2006; Greer et al., 1998). However, Sokmen et al. (2008) has reported that caffeine has ergogenic benefits for repeated bouts of high-intensity exercise ranging in duration from 15 seconds to 3 minutes.

The present study contradicts Wiles et al. (2006) which found a $3 \%$ greater improvement in $1 \mathrm{~km}$ cycling time-trial performance following $5 \mathrm{mg} \cdot \mathrm{kg}^{-1}$ caffeine ingestion. It is important to note that the performance times reported by this latter study (average caffeine time $=71.1$ seconds; average placebo time $=73.4$ seconds) were much faster than in the present study $(82.1 \pm 2.4$ vs. $81.9 \pm 3.9$ seconds for the caffeine and placebo conditions, respectively), which might suggest that the improvement in performance times noted by Wiles et al. (2006) might be due to a higher fitness levels of their participants. In support of this contention, Collomp et al. (1992) reported significantly greater sprint swim performance in trained but not recreational swimmers after the ingestion of $250 \mathrm{mg}$ of caffeine. Therefore, the ergogenic benefits of caffeine may be partially dependent on fitness level. Despite this, the participants in the present study were well trained and it remains to be determined whether the fitness status of the individual and previous experience with sprint cycling interacts with the beneficial effects of caffeine on exercise performance. Furthermore, whether or not there is a particular physiological profile of trained muscle that promotes an ergogenic effect during high-intensity short-term exercise with caffeine consumption is unknown, warranting further investigation. 
There was no difference in the rating of perceived pain between caffeine and placebo conditions. These findings corroborate Astorino et al. (2011), which used the same pain scale as the current study and found that caffeine did not decrease the perception of pain during a high intensity, knee extension exercise protocol. As well, overall fatigue and fatigue localized to the legs were unaltered with caffeine supplementation in the current study. A possible explanation for this lack of apparent change in perceived pain or fatigue with the caffeine may have been related to waiting 5 minutes after the cycling time trial to complete the pain and fatigue scales. This delay was for logistical reasons since the participants were still attached to the metabolic measurement system for the 5 minute active recovery portion of the experiment. As a result, any effect of caffeine on the perception of pain and fatigue that the subjects experienced during or at the very end of the $1 \mathrm{~km}$ time-trial may have been missed.

Caffeine ingestion caused a significant elevation of blood lactate concentration after exercise compared to placebo, which is consistent with previous findings (Bridge \& Jones, 2006; Glaister et al., 2012). Lactate concentrations were significantly increased immediately after and 5 and 15 minutes post-exercise with caffeine ingestion compared to placebo. These results support previous studies, which found caffeine to increase post-exercise lactate concentrations greater than placebo (Anselme et al., 1992; Bridge \& Jones, 2006; Collomp et al., 1992; Cox et al., 2002; Davis \& Green, 2009; Graham, 2001; Graham et al., 1998; Greer et al., 1998; Ivy et al., 2009). The increase in blood lactate may be due to caffeine inhibiting lactate clearance (Graham, 2001), or catecholamines stimulating glycolysis (Cheetham et al., 1986) which might help explain the observed increase in blood lactate without increased performance in the present study.

The findings of the present study confirmed that plasma potassium levels increase with high intensity exercise with the greatest increases occurring immediately following the $1 \mathrm{~km}$ simulated cycling time-trial. In the present study, caffeine consumption elicited a significantly attenuated plasma potassium concentration compared to the placebo condition following the 10 minute warm up which may have been due to caffeine's ability to accelerate muscle potassium handling (Mohr et al., 2011). Mohr et al. (2011) suggested that caffeine may stimulate the $\mathrm{Na}^{+}-\mathrm{K}^{+}$pump indirectly through increased catecholamine response and increased glucose concentrations, or directly in muscle and this may occur even in anticipation of exercise. The ability to maintain forceful muscle contractions at a high frequency is partly dependent on the cycling of potassium from the interstitial space back into the muscle cell following a muscle contraction (Green, 1997). The initial attenuation of potassium efflux with caffeine supplementation may allow for increased cellular concentrations during the early stages of exercise potentially improving sprint performance; however, performance was not altered in the present study.

In the present study high intensity exercise elicited a plasma catecholamine response immediately following and 5 minutes after the $1 \mathrm{~km}$ simulated cycling time-trial and, in addition, norepinephrine was still increased 10 minutes following the time-trial. These findings were consistent with the results of (Zouhal et al., 2008), who reported an increase in catecholamine concentrations with exercise that were closely related to intensity. Caffeine supplementation significantly increased both epinephrine and norepinephrine concentrations immediately following as well as 5 minutes subsequent to the $1 \mathrm{~km}$ simulated cycling time-trial, to a greater extent than in the placebo condition. These findings support previous research following high intensity anaerobic exercise (Bell et al., 2001; Doherty et al., 2002; Greer et al., 1998). The increase in both epinephrine and norepinephrine plasma concentrations with caffeine supplementation may suggest a greater stimulus to the central nervous system. However, it is difficult to discern whether the increased epinephrine and norepinephrine concentrations in blood were due to caffeine directly stimulating the adrenal gland, thus enhancing catecholamine production (Berkowitz et al., 1970), or from the suggested blocking mechanism of the adenosine receptors (Smith, 2003). Furthermore, although catecholamines increased with acute caffeine supplementation, there was no associated elevation in $\mathrm{VO}_{2}$ during the time trial or excess post-exercise oxygen consumption (EPOC) following the time trial.

\subsection{Limitations}

There are some limitations to the present study worth noting. Although there were some significant differential effects of caffeine compared to placebo on several variables, there was no ergogenic benefit to a $1 \mathrm{~km}$ lab based cycling time trial. One aforementioned reason for this may have been due to the fitness level and/or experience of the participants with the $1 \mathrm{~km}$ time trials. In addition, although participants had orientations for familiarization to the $1 \mathrm{~km}$ simulated cycling time-trial and were instructed to perform an all-out effort, a different or a change in pacing strategy may have confounded the results of this study (Glaister et al., 2012). A change in pacing strategy may have masked the ergogenic effects of caffeine. However, the experimental trials were randomly ordered and an order effect analysis revealed that there was not a significant difference between $1 \mathrm{~km}$ finish times between experimental sessions. Although the group mean for the $1 \mathrm{~km}$ cycling performance time was not significantly improved, there may have been a personby-treatment effect for caffeine ingestion since 8 of the 13 (62\%) participants in the present study performed a faster 1 $\mathrm{km}$ sprint under the caffeine condition ( $1.1 \pm 1.0$ seconds). This novel result is also supported by Astorino et al. (2011), who reported meaningful increases in total load lifted in four sets of 70-80\% of 1RM during 3 upper and 1 lower body resistance training exercise to failure after the consumption of $6 \mathrm{mg} \cdot \mathrm{kg}^{-1}$ of caffeine in 9 of 14 of their participants. Certainly additional research is required to confirm this responder phenomenon and variability between individuals. 


\section{Conclusion}

The results of this study suggest that caffeine ingestion at a dose of $5 \mathrm{mg} \cdot \mathrm{kg}^{-1}$ body mass did not improve a lab-based 1 $\mathrm{km}$ cycling time-trial performance. Consumption of caffeine prior to a $1 \mathrm{~km}$ simulated cycling time-trial did, however, attenuate potassium levels in plasma prior to the sprint performance and increased post-exercise blood catecholamine and lactate levels compared to a placebo condition. These metabolic changes were not reflected in an improved $1 \mathrm{~km}$ performance or change in oxygen consumption. Despite the lack of statistical significance for $1 \mathrm{~km}$ performance times between the caffeine and placebo conditions, there did appear to be a person-by-treatment effect, with 8 out of 13 subjects improving their performance times. This information is important for sprint cyclists who may supplement with caffeine expecting performance enhancements as some may benefit from its ingestion and others may not. However, based on the group mean performance times, caffeine consumption prior to a $1 \mathrm{~km}$ simulated cycling time-trial did not produce an ergogenic effect.

\section{Acknowledgments}

This study was designed by DC, GB and DS; data collection was performed by DC, GB and DS; data analyses and interpretation was completed by DC and GB; manuscript preparation was completed by DC, GB and DS. The authors would like to thank Dr. Scott Forbes for his assistance with data collection and manuscript preparation, and Andrea Faid for her phlebotomy skills. Funding for this research was provided by the Sport Science Association of Alberta (SSAA) through the Alberta Sport, Recreation, Parks and Wildlife Foundation.

\section{References}

Anderson, M. E., Bruce, C. R., Fraser, S. F., Stepto, N. K., Hopkins, W. G., \& Hawley, J. A. (2000). Improved 2000meter rowing performance in competitive oarswomen after caffeine ingestion. International Journal of Sport Nutrition \& Exercise Metabolism, 10(4), 464-475.

Anselme, F., Collomp, K., Mercier, B., Ahmaidi, S., \& Prefaut, C. (1992). Caffeine increases maximal anaerobic power and blood lactate concentration. European Journal of Applied Physiology, 65(2), 188-191.

Astorino, T. A., Martin, B. J., Schachtsiek, L., Wong, K., \& Karno, N. (2011). Minimal effect of acute caffeine ingestion on intense resistance training performance. Journal of Strength and Conditioning Research, 25(6), 17521758.

Astorino, T. A., Terzi, M. N., Roberson, D. W., \& Burnett, T. R. (2011). Effect of Caffeine Intake on Pain Perception During High-Intensity Exercise. International Journal of Sport Nutrition \& Exercise Metabolism, 21(1), 27-32.

Bell, D. G., Jacobs, I., \& Ellerington, K. (2001). Effect of caffeine and ephedrine ingestion on anaerobic exercise performance. Medicine \& Science in Sports \& Exercise, 33(8), 1399-1403.

Berkowitz, B. A., Tarver, J. H., \& Spector, S. (1970). Release of Norepinephrine in the Central Nervous System by Theophylline and Caffeine. European Journal of Pharmacology, 10, 64-71.

Bridge, C. A., \& Jones, M. A. (2006). The effect of caffeine ingestion on $8 \mathrm{~km}$ run performance in a field setting. Journal of Sports Sciences, 24(4), 433-439. http://doi.org/10.1080/02640410500231496

Buck, C., Guelfi, K., Dawson, B., McNaughton, L., \& Wallman, K. (2015). Effects of sodium phosphate and caffeine loading on repeated-sprint ability. Journal of Sports Sciences, 33(19), 1971-1979. http://doi.org/10.1080/02640414.2015.1025235

Burke, L. M. (2008). Caffeine and sports performance. Applied Physiology, Nutrition, and Metabolism, 33(6), 13191334. http://doi.org/10.1139/H08-130

Cheetham, M. E., Boobis, L. H., Broks, S., \& Williams, C. (1986). Human muscle metabolism during sprint running. Journal of Applied Physiology, 61(1), 54-60.

Collomp, K., Ahmaidi, S., Chatard, J. C., Audran, M., \& Prefaut, C. (1992). Benefits of caffeine ingestion on sprint performance in trained and untrained swimmers. European Journal of Applied Physiology, 64(4), 377-380.

Cook, D. B., O'Connor, P. J., Oliver, S. E., \& Lee, Y. (1998). Sex differences in naturally occurring leg muscle pain and exertion during maximal cycle ergometry. The International Journal of Neuroscience, 95(3-4), 183-202.

Cox, G. R., Desbrow, B., Montgomery, P. G., Anderson, M. E., Bruce, C. R., Macrides, T. A., ... Burke, L. M. (2002). Effect of different protocols of caffeine intake on metabolism and endurance performance. Journal of Applied Physiology, 93, 990-999.

Crowe, M. J., Leicht, A. S., \& Sprinks, W. L. (2006). Physiological and Cognitive Responses to Caffeine During Repeated, High-Intensity Exercise. International Journal of Sport Nutrition \& Exercise Metabolism, 16(5), 528-544.

Davis, J. K., \& Green, J. M. (2009). Caffeine and Anaerobic Performance: Ergogenic Value and Mechanisms of Action. Sports Medicine, 39(10), 813-832. 
Doherty, M., Smith, P. M., Davison, R. C., \& Hughes, M. G. (2002). Caffeine is ergogenic after supplementation of oral creatine monohydrate. Medicine \& Science in Sports \& Exercise, 34(11), 1785-1792.

Egerton, T., Brauer, S. G., \& Cresswell, A. G. (2009). Fatigue After Physical Activity in Healthy and Balance-Impaired Elderly. Journal of Aging and Physical Activity, 17(1), 89-105.

Elliott, A. D., \& Grace, F. (2010). An examination of exercise mode on ventilatory patterns during incremental exercise. European Journal of Applied Physiology, 110(3), 557-562. http://doi.org/10.1007/s00421-010-1541-4

Glaister, M., Patterson, S. D., Foley, P., Pedlar, C. R., Pattison, J. R., \& McInnes, G. (2012). Caffeine and Sprinting Performance: Dose Responses and Efficacy. Journal of Strength and Conditioning Research, 26(4), 1001-1005.

Graham, T. E. (2001). Caffeine and Exercise: Metabolism, Endurance and Performance. Sports Medicine, 31(11), 785807.

Graham, T. E., Battram, D. S., Dela, F., El-Sohemy, A., \& Thong, F. L. (2008). Does Caffeine Alter Muscle Carbohydrate and Fat Metabolism During Exercise? Applied Physiology, Nutrition \& Metabolism, 33(6), 1311-1318.

Graham, T. E., Hibbert, E., \& Sathasivam, P. (1998). Metabolic and exercise endurance effects of coffee and caffeine ingestion. Journal of Applied Physiology, 85(3), 883-889.

Green, H. J. (1997). Mechanisms of muscle fatigue in intense exercise. Journal of Sports Sciences, 15(3), 247-256. http://doi.org/10.1080/026404197367254

Greer, F., McLean, C., \& Graham, T. E. (1998). Caffeine, performance, and metabolism during repeated Wingate exercise tests. Journal of Applied Physiology, 85(4), 1502-1508.

Gutmann, I., \& Wahlefeld, A. W. (1974). Lactate: Determination with lactate dehydrogenase and NAD. In Methods of Enzymatic Analysis (H.U. Bergmeyer, pp. 1464-1468). New York and London: Verlag Chemie, Weinheim/Academic Press, Inc.

Howley, E. T., Bassett Jr., D. R., \& Welch, H. G. (1995). Criteria for maximal oxygen uptake: review and commentary. Medicine \& Science in Sports \& Exercise, 27(9), 1292-1301.

Ivy, J., Kammer, L., Zhenping, D., Bei, W., Bernard, J., Yi-Hung, L., \& Hwang, J. (2009). Improved Cycling TimeTrial Performance After Ingestion of a Caffeine Energy Drink. International Journal of Sport Nutrition \& Exercise Metabolism, 19(1), 61-78.

Lee, K. A., Hicks, G., \& Nino-Murcia, G. (1991). Validity and Reliability of a Scale to Assess Fatigue. Psychiatry Research, 36(3), 291-298.

Leung, A. W. S., Chan, C. C. H., Lee, A. H. S., \& Lam, K. W. H. (2004). Visual Analogue Scale Correlates of Musculoskeletal Fatigue. Perceptual and Motor Skills, 99(1), 235-246.

Lindinger, M. I., Graham, T. E., \& Spriet, L. L. (1993). Caffeine attenuates the exercise-induce increase in plasma K+ in humans. Journal of Applied Physiology, 74(3), 1149-1155.

Lynge, J., \& Hellsten, Y. (2000). Distribution of adenosine A1, A2A and A2B receptors in human skeletal muscle. Acta Physiologica Scandinavica, 169(4), 283-290.

Mohr, M., Nielsen, J. J., \& Bangsbo, J. (2011). Caffeine intake improves intense intermittent exercise performance and reduces muscle interstitial potassium accumulation. Journal of Applied Physiology, 111(5), 1372-1379. http://doi.org/10.1152/japplphysiol.01028.2010

Smith, A. (2003). Caffeine and Central Noradrenaline: Effects on Mood, Cognitive Performance, Eye Movements and Cardiovascular Function. Journal of Psychopharmacology, 17(3), 283-292. http://doi.org/10.1177/02698811030173010

Sokmen, B., Armstrong, L. E., Kraemer, W. J., Casa, D. J., Dias, J. C., Judelson, D. A., \& Maresh, C. M. (2008). Caffeine Use in Sports: Considerations for the Athlete. Journal of Strength and Conditioning Research, 22(3), 978-986.

Spriet, L. L. (2014). Exercise and Sport Performance with Low Doses of Caffeine. Sports Medicine, 44(S2), 175-184. http://doi.org/10.1007/s40279-014-0257-8

Spriet, L. L., \& Howlett, R. A. (2000). Caffeine. In Nutrition in Sport (pp. 379-392). Oxford; Malden, Mass.: Blackwell Science Ltd.

Wiles, J., Coleman, D., Tegerdine, M., \& Swaine, I. (2006). The effects of caffeine ingestion on performance time, speed and power during a laboratory-base $1 \mathrm{~km}$ cycling time-trial. Journal of Sports Sciences, 24(11), 1165-1171.

Wiles, J. D., Bird, S. R., Hopkins, J., \& Riley, M. (1992). Effect of caffeinated coffee on running speed, respiratory factors, blood lactate and perceived exertion during 1500-m treadmill running. British Journal of Sports Medicine, $26(2), 116-120$.

Zouhal, H., Jacob, C., Delamarche, P., \& Gratas-Delamarche, A. (2008). Catecholamines and the Effects of Exercise, Training and Gender. Sports Medicine, 38(5), 401-423. 